\title{
AVALIAÇÃO IN VITRO DO EFEITO ANTICOLINESTERÁSICO DE FRAÇÕES OBTIDAS DO EXTRATO ETANÓLICO DE Ocotea spixiana
}

\author{
Janaína da Silva Ribeiro'; Mariana Borges Botura²; Raquel Bianca Marchesine de \\ Almeida $^{3}$ e Rodrigo Souza Conceição ${ }^{4}$ \\ 1. Bolsista PROBIC/UEFS, Graduanda em Farmácia, Universidade Estadual de Feira de Santana, e-mail: \\ janaafsa@gmail.com \\ 2. Orientadora, Departamento de Saúde, Universidade Estadual de Feira de Santana, e-mail: mbbotura@uefs.br \\ 3. Doutoranda do Programa de Pós-Graduação em Biotecnologia, Departamento de Ciências Biológicas, Universidade \\ Estadual de Feira de Santana, e-mail: raquelbma87@gmail.com \\ 4. Doutorando do Programa de Pós-Graduação em Biotecnologia, Departamento de Ciências Biológicas, Universidade \\ Estadual de Feira de Santana, e-mail: rodrigoszc@gmail.com
}

PALAVRAS-CHAVE: Planta medicinal, Ocotea spixiana, butirilcolinesterase

\section{INTRODUÇÃO}

Os fármacos com ação anticolinesterásica têm sido utilizados no tratamento de doenças neurodegenerativas associadas à déficits de acetilcolina, principalmente da doença de Alzheimer. A maioria dos medicamentos disponíveis possuem afinidade apenas para a acetilcolinesterase (AChE), porém substâncias com capacidade de atuar sobre as duas colinesterases podem potencializar e prolongar o benefício do tratamento anticolinesterásico (Freitas et al., 2009).

O gênero Ocotea representa um dos principais membros da família Lauraceae. No Brasil, este gênero é representado por cerca de 170 espécies distribuídas em várias regiões do Brasil, inclusive no Nordeste (Brotto e Baitello, 2012). Dentre as atividades biológicas relatadas para algumas espécies de Ocotea, pode-se destacar o efeito carrapaticida (Conceição et al., 2017) e anticolinesterásico (Amoo et al., 2012). Poucos relatos científicos têm sido encontrados sobre as atividades biológicas de Ocotea spixiana. Elevado efeito inibitório in vitro de diferentes extratos dessa espécie sobre a atividade da enzima acetilcolinesterase foi descrito por Cassiano (2014).

O presente estudo teve como objetivos avaliar in vitro o efeito inibitório de frações de O. spixiana frente a butirilcolinesterase $(\mathrm{BChE})$ e realizar a caracterização química da fração mais ativa.

\section{METODOLOGIA}

Coleta e identificação botânica: Caule de $O$. spixiana (aproximadamente $2 \mathrm{Kg}$ ) foram coletadas na região de Morro do Chapéu e identificadas no Herbário da Universidade Estadual de Feira de Santana (HUEFS), onde foi depositada a exsicata de número 205863.

Obtenção dos extratos: $O$ material vegetal foi seco em estufa com temperatura controlada $\left(40^{\circ} \mathrm{C}\right)$ e moído em moinho de facas (tipo Wiley). O material moído foi submetido à maceração com etanol e posteriormente filtrado. $\mathrm{O}$ extrato etanólico bruto foi fracionado por partição líquido-líquido com hexano e acetato de etila. Após este procedimento, os respectivos solventes foram evaporados utilizando rotoevaporador rotativo.

Avaliação in vitro da inibição da atividade da enzima butirilcolinesterase: $\mathrm{O}$ efeito do extrato bruto e frações de $O$. spixiana sobre a atividade da enzima butirilcolinesterase foi avaliado de acordo com o método de Ellman (1961) e modificado por Tan et al. (2014). A enzima utilizada foi a butirilcolinesterase obtida de soro equino. Nos poços de microplacas (96 poços) foram adicionados $140 \mu \mathrm{L}$ de solução tampão fosfato contendo albumina sérica bovina $(0,1 \%), 20 \mu \mathrm{L}$ dos extratos em diferentes concentrações (diluídos em etanol a 10\%), $20 \mu \mathrm{L}$ da enzima (butirilcolinesterase $0,15 \mathrm{U} / \mathrm{mL}$ ), e a placa foi incubada a temperatura ambiente durante 30 minutos. Após esse período, foram adicionados $10 \mu \mathrm{L}$ de solução de iodeto de butiriltiocolina $(14 \mathrm{mM})$ e $10 \mu \mathrm{L}$ de DTNB $(10 \mathrm{mM})$. A eserina $(50 \mu \mathrm{M})$ foi 
utilizada como controle positivo e os controles negativos consistiram na solução tampão fosfato $0,1 \mathrm{M}$ e etanol (1\%). A absorbância foi medida a $405 \mathrm{~nm}$ em leitor de microplaca nos tempos de 0 e 30 minutos. A porcentagem de inibição da colinesterase foi calculada através da comparação das velocidades de reação (hidrólise do substrato) das amostras em relação ao controle negativo.

Caracterização química da fração mais ativa: A fração mais ativa (acetato de etila) foi analisada por Cromatografia Liquida de Alta Eficiência (HPLC/DAD) em cromatógrafo líquido Thermo Scientific, Dionex Ultimate 3000, coluna ACE RP 18 (150 x 4,6 nm).

Análise Estatística: Os resultados foram avaliados pela ANOVA seguido do teste de Tukey ( $p>0,0001$ ), utilizando o programa estatístico Graphprism (versão 5.0).

\section{RESULTADOS E DISCUSSÃO}

$\mathrm{Na}$ avaliação in vitro do efeito inibitório do extrato bruto e frações da $O$. spixiana sobre a atividade da butirilcolinesterase (BChE), foi observado, na maior concentração testada $(1 \mathrm{mg} / \mathrm{mL})$, os seguintes percentuais de inibição: 83,14; 74,22 e 95,29\% para o extrato bruto e frações hexânica e acetato de etila, respectivamente (Figura 1). Todos os tratamentos diferiram estatisticamente do controle negativo (etanol 1\%) (p>0,0001).

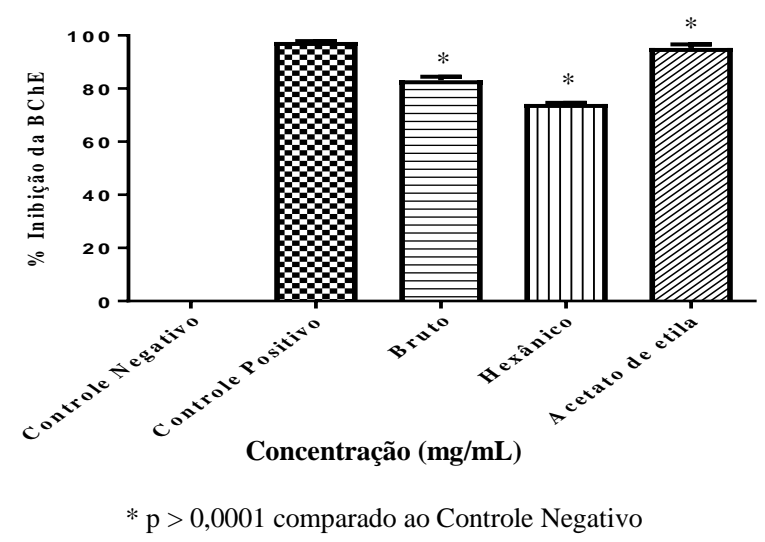

Figura 1: Média e desvio padrão do percentual de inibição da atividade da butirilcolinesterase após exposição ao extrato bruto e frações hexânica e acetato de etila de Ocotea spixiana

A fração acetato de etila apresentou melhor atividade inibitória sobre a $\mathrm{BChE}$, e foi selecionada para a realização de novos ensaios com diferentes concentrações $(0,0625$ a 1 $\mathrm{mg} / \mathrm{mL}$ ) para avaliação da relação concentração-dependência. Na figura 2, observa- se um aumento do efeito inibitório da fração acetato de etila frente a BChE em concentrações mais elevadas, demonstrando uma ação concentração-dependente. Os resultados desta fração na concentração de $1 \mathrm{mg} / \mathrm{mL}$ não diferiram estatisticamente ( $p>0,0001)$ do controle positivo (eserina/50 $\mu \mathrm{M})$.

De acordo com Vinutha et al. (2007), a atividade anticolinesterásica de um extrato pode ser considerada como potente quando o percentual de inibição da atividade enzimática for maior ou igual a $50 \%$, moderada quando estiver entre 30 e $50 \%$ e fraca quando menor que $30 \%$. No presente estudo, os tratamentos com o extrato e frações de $O$. spixiana resultaram em inibição da BChE superior a 50\%. O estudo anterior sobre o efeito in vitro de extratos das folhas de $O$. spixiana $(1 \mathrm{mg} / \mathrm{mL})$ frente a acetilcolineterase também revelou atividade anticolinesterásica para os seguintes extratos: etanólico $(45,79 \%)$, hexânico $(58,55 \%)$ e acetato de etila $(50,73 \%)$ (Cassiano, 2014). No entanto, esses percentuais de inibição foram inferiores aos resultados encontrados no presente trabalho. Estas variações podem estar 
relacionadas com as diferenças do material vegetal (folhas e caule) e com o tipo de colinesterase avaliada.

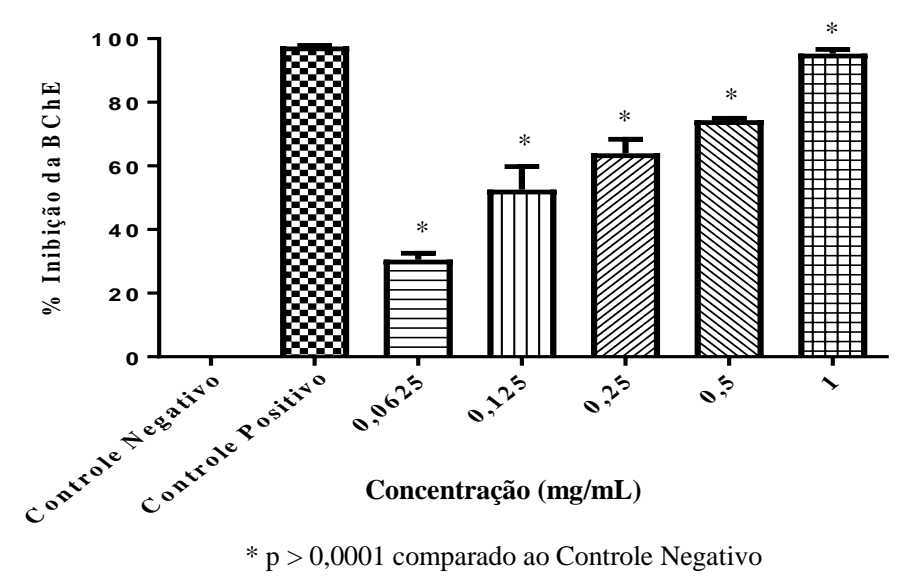

Figura 2: Média e desvio padrão do percentual de inibição da atividade da butirilcolinesterase após exposição à fração acetato de etila de Ocotea spixiana

A fração de $O$. spixiana mais ativa (acetato de etila) foi analisada por Cromatografia Liquida de Alta Eficiência e foi possível identificar a presença dos compostos benzaldeído, galoil éster (tanino) e calycosin (isoflavona). A identificação destas substâncias (Figura 3) foi realizada com base na análise dos seus espectros em comparação com dados da literatura (Tabela 1). Outros estudos têm relatado a presença de compostos fenólicos associados ao efeito anticolinesterásico (Cassiano, 2014) e isoflavonas com ação bactericida (Oliveira, 2014) em espécies de Ocotea.

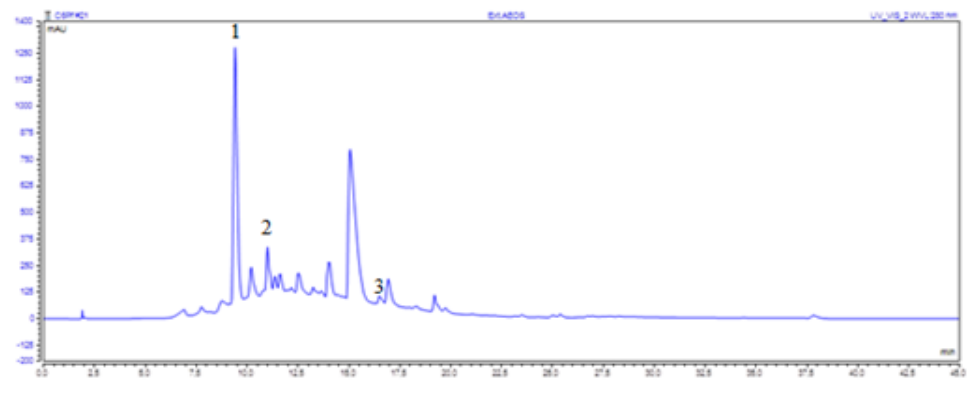

Figura 3: Cromatograma (HPLC-DAD) obtido a partir da fração acetato de etila de Ocotea spixiana

Tabela 1. Identificação dos compostos a partir da fração acetato de etila de Ocotea spixiana.

\begin{tabular}{ccccc}
\hline Picos & Tr $(\mathbf{m i n})$ & UV $\lambda \mathbf{m a x}(\mathbf{n m})$ & Identificação & Referência \\
\hline 1 & 9,39 & $242,5-281,7$ & Benzaldeído & Kumar et al. \\
& & & & $(2006)$ \\
2 & 11,01 & $225,3-281,8$ & Galoil éster & Bochi et al. $(2015)$ \\
3 & 16,51 & $230,6-267,3$ & Calycosin & Yen et al. $(2012)$ \\
\hline
\end{tabular}

\section{CONSIDERAÇÕES FINAIS}

A partir dos resultados obtidos neste estudo pode-se concluir que a espécie Ocotea spixiana possui pronunciado efeito inibitório in vitro frente a enzima butirilcolinesterase, 
sendo a fração acetato de etila a mais ativa. A análise química desta fração indicou a presença de compostos fenólicos, que podem estar associados com o efeito anticolinesterásico desta espécie vegetal.

\section{REFERÊNCIAS}

AMOO, S.O. 2012. Antioxidant and acetylcholinesterase-inhibitory properties of long-term stored medicinal plants. BMC Complementary and Alternative Medicine 12(1): 1-9.

BOCHI, V. S.; GODOY, H. T.; GIUST, M. M. 2015. Anthocyanin and other phenolic compounds in Ceylon gooseberry (Dovyalis hebecarpa) fruits. Food Chemistry 176(5): 234243.

BROTTO, M.L, BAITELLO, J.B. 2012. Uma espécie nova de Lauraceae da floresta atlântica do Brasil. Rodriguésia 63(3): 579-585.

CASSIANO, D. S. A. 2014. Estudo bioguiado através da atividade anticolinesterásica e da análise por CLAE-DAD e CLAE-DAD-EM/EM DE Ocotea spp. (Lauraceae). Universidade Estadual de Feira de Santana, Tese.

CONCEIÇÃO, R.S. 2017. In vitro acaricide activity of Ocotea aciphylla (Nees) Mez. (Lauraceae) extracts and identification of the compounds from the active fractions. Ticks and Tick-borne Diseases 8: 275-282.

ELLMAN, G. L. 1961. A new and rapid colorimetric determination of acetylcholinesterase activity. Biochem. Pharmacol. (7): 88-95.

FREITAS, H. F.; PAZ, O. S.; CASTILHO, M. S. 2009. Estudos de QSAR 3D para um conjunto de inibidores de butirilcolinesterase humana. Química Nova 32(8): 13-22.

KUMAR, S. 2006. Spectroscopy of Organic Compounds in Organic Chemistry. India: Ebooks.

OLIVEIRA, R. P. R. F. 2014. Desenvolvimento de nanoemulsões contendo flavonoides de Ocotea notata (Ness) Mez e avaliação de atividades biológicas. Universidade Federal Fluminense, Tese.

TAN, W.N.; KHAIRUDDEAN, M.; WONG, K.C.; KHAW, K.Y.; VIKNESWARAN, M. 2014. New cholinesterase inhibitors from Garcinia atroviridis. Fitoterapia 97: 261-267.

VINUTHA, B.; PRASHANTH, D.; SALMA, K.; SREEJA, S. L.; PRATITI, D.; PADMAJA, R.; RADHIKA, S.; AMITA, A.; VENKATESHWARLU, K.; DEEPAK, M. 2007. Screening of selected Indian medicinal plants for acetylcholinesterase inhibitory activity. Journal of Ethnopharmacology 109(3) 65-71.

YEN, M.; YANG, W. Z.; X, D. K. CHENG, B. J.; FENG, J. A.; ZHAON, Y.Y. 2012. Characterization of flavonoids in Millettia nitida var. hirsutissima. Journal of Pharmaceutical Analysis 24(2) 35-42. 